\title{
DR-21
}

\section{NEW SILVER NANOCOMPOSITES BASED ON AZANORBORNENE COPOLYMERS}

\section{N. Gorbunova}

Institute of Technical Chemistry, Ural Branch of Russian Academy of Sciences, 3 Korolev St., Perm 614013, Russia. E-mail: mngorb@yandex.ru

Abstract. The copolymers of N-methyl-2-azanorbornene-5 (MAN), N-benzyl-2-azanorbornene5 (BAN), Nallyl-2-azanorbornene-5 (AAN) and N-(2-azanorbornene-5)methylacetate (MAAN) with acrylic acid (AA) have been obtained by free radical polymerization.

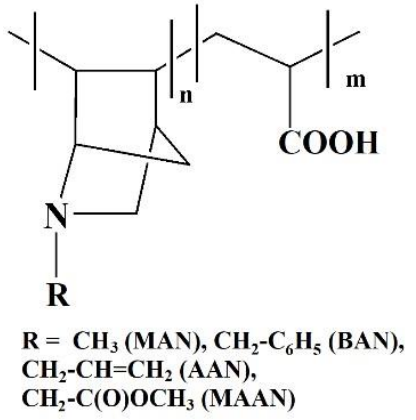

New silver nanocomposites based on new copolymers have been obtained by the reduction of $\mathrm{AgNO}_{3}$ with $\mathrm{NaBH}_{4}$ in copolymer solution. Reaction proceeds via formation of the stable dark brown sols, from which silver nanocomposites were separated.

The content of silver in the composites was found to be $8,13,11$ and $24 \%$ for MAN, BAN, AAN and MAAN respectively.

UV-spectroscopy, an atomic force microscopy and scanning electron microscopy techniques were used to characterize the formation of silver nanoparticles in copolymers. The average silver particle size ranged from 15 to $52 \mathrm{~nm}$, with the corresponding UV-vis absorption peak position at 400-412 nm (Figure 1).

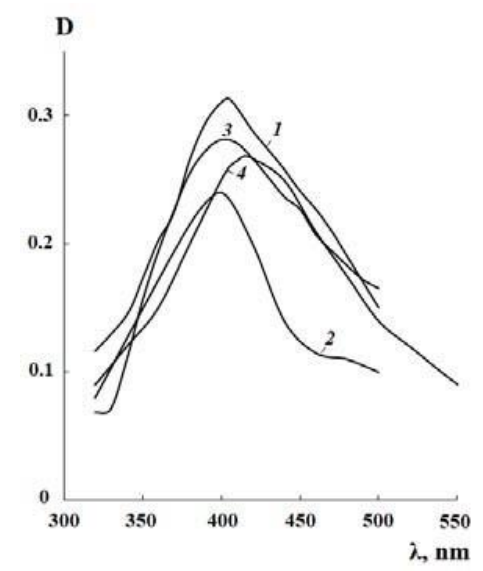

Figure 1. UV extinction spectra of nanocomposite water solution: $1-$ poly(AA-MAN), $C=5 \cdot 10^{-3} \mathrm{~mol} / 1 ; 2$ - poly(AA-BAN), $\mathrm{C}=10^{-4} \mathrm{~mol} / \mathrm{l} ; 3-$ poly(AA-AAN), $\mathrm{C}=10^{-3} \mathrm{~mol} / \mathrm{l} ; 4-\operatorname{poly}(\mathrm{AA}-\mathrm{MAAN}), \mathrm{C}=5 \cdot 10^{-4} \mathrm{~mol} / \mathrm{l}$.

SEM results prove the obtaining of nanocomposites with regular narrow-dispersed distribution of silver nanoparticles in polymer matrice. Nanoparticles of spheric and elliptic forms were obtained.

Investigation showed that new nanocomposites have exhibited significant cytotoxic activitytowards rhabdomyosarcoma and melanoma line cells and can be used for medical applications. 